\title{
Mobile phones and health: A literature overview
}

\author{
Christian P. Karger \\ Deutsches Krebsforschungszentrum \\ Abteilung Medizinische Physik in der Strahlentherapie \\ Heidelberg
}

\begin{abstract}
The rapidly evolving mobile phone technology raised public concern about the possibility of associated adverse health effects. The current body of evidence is summarized addressing epidemiological studies, studies investigating adverse biological effects, other biological effects, basic mechanisms and indirect effects. Currently, the balance of evidence from epidemiological studies suggests that there is no association between mobile phone radiation and cancer. This finding is consistent with experimental results. There is some evidence for biological effects, which, however, are not necessarily hazardous for humans. No basic mechanisms of biological effects have been consistently identified yet. Using a mobile phone while driving a car is significantly associated with a higher risk of vehicle collisions, independently of the use of hands-free kits. Medical equipment or implanted pacemakers may be affected by mobile phone radiation under very specific conditions. Current studies, however are affected by several limitations and do not generally exclude any increased health risk. Further high-quality research is therefore necessary. Furthermore, it is important that the results of scientific research are communicated to the public in a transparent and differentiated way.
\end{abstract}

Keywords: Mobile phone, hand-held cellular telephone, microwaves, non-ionizing radiation, radiation risk

\section{Mobiltelefone und Gesundheit: Ein Literaturüberblick}

\section{Zusammenfassung}

Die rasante Entwicklung der Mobilfunktechnologie hat in der Öffentlichkeit zu Besorgnis wegen der Möglichkeit einer assoziierten Gesundheitsschädigung geführt. Der Stand der Forschung bei epidemiologischen Studien, Studien zu schädlichen biologischen Effekten, zu sonstigen biologischen Effekten, zu Wirkungsmodellen und indirekten Effekten wird zusammengefasst. Die Ergebnisse epidemiologischer Studien lassen gegenwärtig nicht auf einen Zusammenhang zwischen der Mobilfunkstrahlung und Krebs schließen. Dieses Ergebnis ist konsistent mit Ergebnissen experimenteller Untersuchungen. Es gibt einige Hinweise auf biologische Effekte, die jedoch nicht notwendigerweise eine Gefahr für den Menschen darstellen. Bisher wurde kein mechanistisches Wirkungsmodell zweifelsfrei etabliert. Der Gebrauch eines Mobiltelefons beim Autofahren ist mit einem signifikant höheren Unfallrisiko verbunden. Die Risikoerhöhung ist dabei unabhängig vom Gebrauch einer Freisprecheinrichtung. Medizinische Geräte und implantierte Herzschrittmacher können unter bestimmten Umständen gestört werden. Die gegenwärtigen Studien besitzen jedoch verschiedene Limitationen und schließen generell ein erhöhtes Gesundheitsrisiko nicht aus. Weitere qualitativ hochwertige Forschung ist daher erforderlich. Darüber hinaus ist es notwendig, dass die Forschungsergebnisse auch in der Öffentlichkeit transparent und differenziert dargestellt werden.

Schlüsselwörter: Mobiltelefone, Handy, Mikrowellen, nichtionisierende Strahlung, Strahlenrisiko 


\section{Introduction}

The rapidly evolving mobile phone technology raised public concern about the possibility of associated adverse health effects. World wide, more than 500 million mobile phones are in use and the number is expected to increase to 1.6 billion in 2005 [107]. To operate these handheld devices, a dense network of base stations is needed to transmit the phone calls. Currently, there are more than 60 million mobile phone users and more than 50000 base stations in Germany [91]. The number of base stations is expected to increase within the next years due to the invention of the „Universal Mobile Telecommunications System (UMTS)“ technology [21]. The UMTS-technology belongs to the $3^{\text {rd }}$ generation of mobile communication systems and allows much higher data transfer rates which are required e. g. for multi-media applications.

Mobile telephony is based on transmission of microwaves with frequencies between 450 and $1800 \mathrm{MHz}$. If biological systems are exposed to this type of non-ionizing radiation, energy is transferred to the system. The question has been raised, whether, this energy transfer leads to biological effects and, moreover, if there are adverse health effects in humans associated with microwave exposure. A proven association between microwave exposure and adverse health effects would, of course, be of high impact for public health and it was questioned, if existing exposure limits are sufficient to avoid adverse effects in humans.

The research activities in the field of microwave exposure may be classified into five categories, each of them addressing a specific question:

1. Search for mechanisms by which microwaves can affect biological systems.

2. Search for effects in biological systems. These effects are not necessarily related to adverse health effects in humans, but may help to identify the underlying response mechanism in biological systems

3. Search for adverse biological effects with high impact on human health.
4. Epidemiological studies searching for an association between mobile phone radiation and cancer. Positive evidence from such studies would be of highest importance for human health.

5. Indirect effects on human health which do not result directly from an interaction between the mobile phone radiation the biological system.

This paper aims to give an overview on the scientific literature addressing these categories. Special attention is given to a possible association between mobile phone radiation and cancer.

\section{Materials and Methods}

In the following sections, the basic characteristics of the mobile phone technology and some dosimetric aspects of microwave radiation are briefly described. For a more detailed description of these technical aspects, the reader is referred to the literature $[4,21,51,71,93]$.

\section{Mobile phone technology}

Mobile telephony is based on microwave radiation (radiofrequency radiation) being transmitted between the handheld device and base stations distributed allover the country. Table 1 gives an overview over the main characteristics of the transmitted radiation used in Germany $[4,51,91]$. As the German C-network is not in operation anymore, most mobile phones use the D- or E-network. The UMTS-network is currently under development.

While the C-network operates in an analogue mode, the Dand E-network used today operate in a digital mode, where the radiation is additionally modulated by low frequencies of 8 and $217 \mathrm{~Hz}$ [93], respectively. Cordless telephones operate at frequencies of about $1800 \mathrm{MHz}$ (similar to the E-network), the transmitted power, however, is lower, since these devices are used only with short distances to the base stations, e.g.

Table 1 Characteristic features of microwave radiation used for mobile telephony in Germany [4,51,91].

\begin{tabular}{|c|c|c|c|c|c|}
\hline \multirow[t]{2}{*}{ Network } & \multirow[t]{2}{*}{ Type } & \multirow{2}{*}{$\begin{array}{c}\text { Frequency } \\
{[\mathrm{MHz}]}\end{array}$} & \multirow{2}{*}{$\begin{array}{l}\text { Photon energy } \\
{[\mu \mathrm{eV}]}\end{array}$} & \multicolumn{2}{|c|}{ Transmitted power [W] } \\
\hline & & & & Handheld & $\begin{array}{l}\text { Base station } \\
\text { (per channel) }\end{array}$ \\
\hline$C^{a)}$ & analogue & 450 & 2 & $<0.75$ & $8 / 35$ \\
\hline $\mathrm{D}$ & digital & 900 & 4 & $<2$ & $10(\max .50)$ \\
\hline$E$ & digital & 1800 & 7 & $<1$ & 10 \\
\hline UMTS ${ }^{b}$ & digital & $1900-2000$ & 8 & $<1$ & $<20$ \\
\hline \multicolumn{6}{|c|}{ Cordless telephone } \\
\hline DECT & digital & 1800 & 7 & 0.25 & - \\
\hline
\end{tabular}

a) Not in operation anymore

b) Almost no dedicated studies on biological effects available yet 
within the home of the user. The UMTS technology also operates in a digital mode using a similar radiation power at slightly higher frequencies as compared to the E-network. Radiation produced by the UMTS-technology may or may not be modulated by low frequencies [74].

Although the transmitted power of the base stations is much higher than that of the handheld device, the exposure of the user by the base stations is much less due to the larger distance as compared to the handheld device [91]. Nevertheless, the base stations are a matter of public discussion, probably because they are visible for everyone and because individuals can not decide, if they are willing to accept a potential risk by exposure from these base stations.

\section{Dosimetry for microwaves}

Microwave radiation is attenuated by material and as a consequence there is an energy transfer to the material. The attenuation rises with increasing frequency and depends on the dielectric properties and the size of the absorber. While the maximum absorption for adults is found between 30 and $100 \mathrm{MHz}$, the absorption in children receives a maximum at higher frequencies of $100-400 \mathrm{MHz}$ [4]. For mice, the maximum is received at even higher frequencies of $2450 \mathrm{MHz}$ [4]. In addition, the attenuation of the radiation leads to an inhomogeneous exposure of the irradiated object. As a consequence, it is difficult to transfer dosimetric conditions from experiments with small animals to humans.

For microwaves, the dosimetric quantity of interest is given by the specific absorption rate (SAR), which is defined by the absorbed power per unit mass (given in units of $\mathrm{W} / \mathrm{kg}$ ) $[4,21,71]$. The SAR is difficult to determine and may be estimated for example by measurements of the electric field strength of the radiation, the temperature increase or by numerical simulations [71].

The International Commission on Non-Ionizing Radiation Protection (ICNIRP) has recommended limits (Table 2) for the SAR $[4,93]$. These Limits are based on the knowledge, that an exposure of the whole body with an average SAR of 4 $\mathrm{W} / \mathrm{kg}$ will lead to a temperature rise of $1^{\circ} \mathrm{C}$ [16]. Starting from this value, the whole body limits for occupational and public exposure are then reduced by a factor of 10 and 50, respectively. To avoid small sized hot spots, additional limits are provided for the SAR averaged over a mass of $10 \mathrm{~g}$. These dose limits were introduced to prevent thermal effects in humans.
Below these exposure limits, the maximum temperature increase in the brain of a mobile phone user was found to remain below $0.1^{\circ} \mathrm{C}[93,100,105]$. Since such a small rise in temperature is considered to be physiologically irrelevant, it was concluded that a potential lasting effect in humans is very unlikely to result from thermal effects [100]. The discussion on potential adverse health effects originating from mobile phone use is therefore focused on the possible existence of non-thermal effects in biological systems. Nevertheless, it cannot be completely ruled out that subtile biological effects may occur also below a temperature increase of $0.1^{\circ} \mathrm{C}$.

\section{Scientific literature}

This paper summarizes the main results of studies on biological effects of mobile phone radiation published until 2004. Since the UMTS-technology is rather new, there are almost no publications on biological effects dedicated to this technology. Investigations of biological effects associated with this technology are therefore not addressed in this paper.

Although the results of several types of investigations are described, the paper especially focuses on experimental and epidemiological evidence for a possible association between mobile phone radiation and cancer. It was not intended to provide an independent evaluation or assessment of existing studies. This paper is rather based on existing reviews and reports of expert panels $[28,93]$. One of the most well known expert panels is the Independent Expert Group on Mobile Phones (IEGMP) [93] and many conclusions drawn in this paper refer to the report of this expert panel. More recently published reviews $[15,17,25,65,69,70,91]$ and reports of expert panels $[74,75,82]$, however, were also considered. In addition, original studies are addressed, if they are of special interest.

\section{Results and Discussion}

\section{Response mechanisms}

The photon energy of microwave radiation is in the range of some $\mu \mathrm{eV}$ (Table 1). This energy is far below the energy even of weak chemical bindings or that of other degrees of freedom such as molecular rotations or vibrations. The photon energy is even some orders of magnitude smaller than the

Table 2 Dose limits recommended by the ICNIRP [93].

\begin{tabular}{|c|c|c|c|c|}
\hline \multirow[t]{2}{*}{ Tissue region } & \multicolumn{2}{|c|}{ SAR limit [W/kg] } & \multicolumn{2}{|c|}{ Averaging parameters } \\
\hline & Occupational exposure & Public exposure & Mass [g] & Time [min] \\
\hline Whole body & 0.4 & 0.08 & - & 6 \\
\hline Head, trunk & 10 & 2 & 10 & 6 \\
\hline Limbs & 20 & 4 & 10 & 6 \\
\hline
\end{tabular}


mean kinetic energy of the atomic particles at room temperature, which is in the range of $26 \mathrm{meV}$. Therefore, modifications of chemical bindings, at least by single photons, are impossible and tissue heating may only occur at high SAR values. As the temperature rise in the brain due to a mobile phone was found to be less than $0.1^{\circ} \mathrm{C}[93,100,105]$, lasting effects due to heating are not expected.

Some interaction mechanisms have been proposed to explain, how microwaves can induce non-thermal effects in biological systems $[7,57,93]$. These include the application of non-linear dynamics [57] or resonance and amplification effects [7]. For example, Bohr et al. [7] showed theoretically, that the torsional modes of topologically constrained chain molecules (e. g. folded proteins) may be excited by microwaves in the GHz-range and that this excitation may lead to conformational changes of the protein. This theory was later on supported by experimental results, demonstrating that microwaves affect the kinetics of folding and unfolding of the protein $\beta$-Lactoglobulin [6]. The link between experimental effects like these and mechanistic theories, however, is still weak. Up to now, there is only little evidence supporting resonant behaviour of biological systems and further research on the proposed mechanisms is necessary [93].

\section{Biological effects}

\section{$\mathrm{Ca}^{2+}$-efflux in nervous tissue}

$\mathrm{Ca}^{2+}$-ions play an important role in the signal chain of neurons and other cells. There is some evidence that microwave exposure of brain tissue may increase the calcium efflux from cells $[28,47,93]$. Experiments demonstrated increased calcium efflux for an extremely low frequency modulated $147 \mathrm{MHz}$ microwave carrier frequency. This effect peaked at modulation frequencies around $16 \mathrm{~Hz}$. The unmodulated carrier frequency did not show this effect. Moreover, for $450 \mathrm{MHz}$ carrier frequencies modulated at $16 \mathrm{~Hz}$, there appears to be a power density window between 1 and $10 \mathrm{~W} / \mathrm{m}^{2}$, below and above which the effect does not occur. At higher frequencies, the evidence is inconclusive with respect to the available data [28]. These results are difficult to interpret and their relevance to mobile phone technology is unclear [93]. They demonstrate, however, that an additional extremely low frequency modulation of a microwave carrier frequency may lead to changes in the response of biological systems.

An increased calcium efflux may stabilize neurons and reduce their excitability. As long as there is no significant temperature rise, the exposure does not produce obvious effects [93]. Effects on neurotransmitters have also been observed [47]. Most of them were probably associated with responses to temperature changes [93].

\section{Permeability of the blood-brain-barrier}

The influence of microwave exposure on the permeability of the blood brain barrier has been investigated [28,47,93], as several severe diseases such as multiple sclerosis, Parkinson disease and schizophrenia have been associated with an increased permeability of the blood-brain-barrier [91]. In animal experiments, Salford et al. found an increased permeability of the blood-brain-barrier [86] for continuous as well as for pulsed microwave radiation, which was also associated with neuronal damage [87]. Studies of other authors, however, could not confirm these findings $[27,96]$. Fritze et al. found a significant increased permeability only for the highest SARvalue of $7.5 \mathrm{~W} / \mathrm{kg}$, but not for lower values [33]. Such high SAR-values, however, do not occur when using mobile phones [91] and it was suspected that the positive findings may have been produced by thermal effects [96].

\section{Changes in Melatonin level}

The hormone Melatonin is secreted by the pineal gland and controls the day-night-cycle. There are reports that extremely low frequencies may affect the pineal gland function. As the photon energy of microwaves is much higher, the question has been raised if microwaves can also influence the pineal gland. Up to now, few studies have been performed and the results do not suggest that the melatonin production is affected [93].

\section{Changes in EEG- and sleep-parameters}

The electroencephalogram (EEG) reflects synchronous activity in large populations of cortical neurons and the influence of microwave exposure on EEG- and sleep-parameters was investigated $[17,47,85,93]$. The investigations produced somewhat contradicting results $[17,93]$.

Changes in the spontaneous EEG of waking subjects after mobile phone radiation exposure was reported by von Klitzing [102]. Mann and Röschke [68] found a pronounced sleep-inducing effect with shortening of sleep-onset latency as well as a suppression of REM-sleep. The same group, however, could not replicate their findings in later studies [103,104]. Several biological and methodological factors were discussed as possible reasons [103].

Boberley et al. reported an increased amount of waking after sleep-onset and a transitory increase of the spectral power of EEG in the non-REM phase after exposure to pulse-modulated microwave radiation [8]. In a later work of the same group, however, only the increased spectral power could be confirmed [49]. Moreover, the effect occurred only for pulsemodulated but not for continuous wave radiation [50]. An increase in the waking regional cerebral blood flow was also recognized [50].

Task-related changes in the EEG after auditory or visual stimuli were also compared for exposed and non-exposed conditions. Eulitz et al. reported a modulation in the high-frequency bands of the EEG after task-relevant but not after standard auditory stimuli [26]. Freude et al. found an effect on preparatory slow brain potentials for visual monitoring tasks, but not for less demanding tasks such as finger movements [31,32]. Krause et al. reported event-related changes of the desynchonisation/synchonisation responses in the EEG for auditory and visual memory tasks $[61,62]$. In a recently 
published double-blinded replication study, however, Krause et al. could not reproduce their earlier findings [60]. Recently, Hamblin et al. reported alterations of amplitudes and latency times of event-related potentials in the EEG for auditory tasks [39].

Overall, it was concluded that exposure to mobile phone radiation might influence brain function and that further research is needed. It is emphasized, however, that even if such effects will be proven, their biological and clinical relevance is still unclear [93].

\section{Behavior changes}

Analysis of the behavior of exposed laboratory animals has been used to assist the establishment of save exposure limits for humans $[15,16]$. Significant effects have been reported if body heating took place. There is, however, also evidence for behavior and associated biochemical changes at or below the occupational exposure limits [15,28]. The causal mechanism is unclear but could include a small localized heating effect [93].

Investigations of mobile phone radiation on cognitive function in man have been carried out and a decrease in reaction time was reported $[58,59,77]$. A double-blinded multicentric replication study, however, failed to confirm these findings [38]. Recently, a carefully designed study on the influence of mobile phone radiation on well-being and cognitive function of human subjects with and without subjective complaints has found significant effects, especially for the new UMTSsystem [109]. The authors concluded that further research in this area is justified and recommendations where to focus on are given. It was especially pointed out that the positive findings need to be confirmed by an independent group of scientists [109].

\section{Influence on blood-pressure}

An influence of microwaves from mobile phones on resting blood pressure was reported by Braune et al. [10]. Systolic and diastolic blood pressure was found to be significantly higher in the exposed as compared to the placebo group. A more recent study published by the same author [9] also found a significant increase of blood pressure which, however, was independent from the exposure pattern by the mobile phone radiation. It was therefore concluded that mobile phone radiation does not affect blood pressure in humans. A recently published randomized double-blinded study also did not find any effect of mobile phone radiation on blood pressure [94].

\section{Evidence for non-thermal effects in experimental systems}

De Pomerai et al. published an experiment [18] demonstrating that non-thermal exposure of a transgenic worm to microwaves leads to a significant increase of heat-shock protein secretion. Recently, the same author reported that small thermal effects contributed to this finding [19]. The experimental results were reproduced for a microwave induced temperature in- crease of $0.25^{\circ} \mathrm{C}$, however, not for an increase of $0.12^{\circ} \mathrm{C}$. Even though the relevance of this experiment for human is not clear, these results show that biological effects from mobile phone radiation may originate from small temperature variations.

\section{Adverse health effects}

\section{Subjective symptoms}

Subjective symptoms such as headache, feelings of discomfort and warmth on the ear were reported by users of mobile phones. A significant increased prevalence for headache was found for mobile phone users, which was associated with the duration of the phone calls per day [12]. In a comparison between analogue and digital mobile phone systems, the prevalence for subjective symptoms was found to be higher for the analogue than for the digital system $[76,88]$. Interestingly, the study was initiated under the opposite hypothesis. Digital mobile phones showed a lower risk for sensations of warmth on the ear and partly for fatigue and headache. A significant association of these symptoms with exposure time was found. Many other factors than electromagnetic fields, however, could have produced these findings and all studies lack strength in providing cause and effect relationships [17].

\section{Ocular effects}

Microwave exposure of the eye is of special concern for two reasons: firstly, the eye has a reduced (or even no, in the case of the lens) blood supply which reduces heat dissipation, secondly it is located superficially and therefore receives higher SAR values in comparison to deep-seated tissues. The possibility of adverse effects (e.g. cataracts in the lenses) was investigated in several studies. Although, adverse ocular effects were only found for SAR values well above values that occur in the eye from the use of mobile phones [22], there remains some concern about possible adverse health effects from high peak-power, pulsed microwave radiation [93]. Current results, however, support the conclusion that clinically significant ocular effects do not occur for low-level microwave radiation [22].

\section{Genotoxic effects}

There are more than 100 studies investigating genotoxic effects of microwave radiation and several reviews of these studies are available $[11,28,48,69,93,101]$. Most of the studies were hazard identification studies and focussed on the possibility of gene mutation, chromosome alterations, induction of DNA repair processes and cell transformation assays $[11,48,69]$. Although the majority of these studies did not demonstrate genotoxic effects, there have been some positive results. A closer inspection of these studies indicated that at least some of the effects were produced by hyperthermia. Others were attributable to deficiencies of the experimental design, which may have lead to sporadic positive results. Although the existence of genotoxic effects can not completely 
be ruled out, the weight of evidence suggests that there is no significant risk associated with non-thermal microwave exposure $[11,48,69,71]$. The investigation of genotoxic effects was also aim of the REFLEX-project which was initiated within the framework of the European Community. The results of this project will be published in the near future.

\section{Cell proliferation}

While the existence of direct genotoxic effects appears to be unlikely, non-thermal effects on cell proliferation may still be possible. In-vitro studies of microwave radiation effects on cell growth, survival or proliferation resulted in conflicting results and do not demonstrate convincing and consistent evidence on cell proliferation under conditions of the mobile telephone technology [93]. Cell proliferation is also one of the endpoints studied by the REFLEX-project.

\section{Tumor promotion and progression}

Several studies in animals have been performed to investigate a potential association between long-term low-level microwave exposure and tumor promotion or tumor progression $[1,23,29,30,64,79,95]$. Most of these studies did not find a significant difference between the exposed and the control groups $[1,29,30,64,95]$. In a lifespan study, however, Repacholi et al. [79] exposed transgenic mice, which are moderately predisposed to develop lymphomas, to $900 \mathrm{MHz}$ microwave radiation. At 18 months, the lymphoma risk was found to be significantly higher in the exposed mice than in the controls $(43 \%$ vs. $22 \%$ ).

For several years, this result was considered as most important evidence for a possible connection between microwave exposure and tumor promotion or progression [81]. The design of the experiment, however, had some shortcomings with respect to dosimetry. Since the mice were not fixed during exposure, the SAR varied between 0.008 and $4.2 \mathrm{~W} / \mathrm{kg}$ and hot spots within the animals could not be ruled out. Moreover, it was objected [93] that the lymphoma incidence was rapidly increasing at the end of the experiment in both, the exposed and the sham-exposed animals.

Recently, the experiment of Repacholi et al. [79] was replicated by Utteridge et al. [97], indicating that long term microwave radiation does not increase lymphoma incidence. The experiment included 1600 mice and in contrast to the initial study, the animals were fixed during exposure and 4 different dose levels between 0.25 and $4 \mathrm{~W} / \mathrm{kg}$ were used. Two groups of sham-treated animals were used, one with fixed and one with free moving animals. The experiment was performed for the initial transgenic strain as well as for the wild-type of the same strain. Great effort was spent on precise SAR measurements and in contrast to the initial study, all animals were necropsied.

The publication was controversially discussed $[35,36,63$, $66,67,98,99]$. Since some exposure conditions were not exactly the same as in the initial study, the comparability of both studies was questioned $[63,66,67]$. The most important objection, how- ever, was that the lymphoma incidence for the sham-treated transgenic mice in Utteridge et al. was significantly higher than that in Repacholi et al. (74\% vs. $28 \%$ ) [35,67]. In his reply [98], Utteridge solved this discrepancy by reprinting the survival curves as a function of age instead of the initially used days of exposure (which excluded weekends and public holidays). After that, the incident rates agreed with those of Repacholi et al. In additional communications [36,99], some more details have been clarified.

Finally, two recently published studies with similar experimental design also showed no significant effect [1,64]. In conclusion, the weight of evidence does not prove that microwave radiation adversely affects tumor promotion or progression [23].

\section{Epidemiological studies}

Epidemiological studies of microwave exposure and human cancers include studies of military and civilian groups, people who live near television or radio transmitters and users of mobile phones [25]. The results of these studies have been reviewed in several publications $[24,25,48,70,71,83]$.

\section{Studies on military and civilian people}

Studies on military and civilian people included for example investigation of radar laboratory workers, employees of the American embassy building in Moscow, which were subjected to microwave exposure between 1953 and 1976, and other occupational groups dealing with microwave radiation $[24,25,48$, 71]. In addition, incident rates for leukemia and solid tumors were investigated near television and radio transmitters. The evidence of these studies, however, is weak in regard to its inconsistency and an association between microwave exposure and cancer can not be concluded. Detailed data on individual exposure are lacking and some of the studies are suspected to be biased by other factors [24,71]. No causal implications could be drawn from these studies [25].

\section{Dedicated mobile phone studies}

Meanwhile, several epidemiological studies dedicated to microwave exposure from mobile phones are available $[2,20,40,43$, $48,52,56,73,84]$. Most of the studies focus on brain tumors (Table 3).

A cohort study including more than 250000 users of mobile phones was performed by Rothman etal. [84]. This study compared the overall mortality for users of hand-held and non-handheld (primarily car) telephones. The latter were considered to be non-exposed due to the larger distance of the antenna. No significantly increased mortality rate was found for hand-held devices (mortality ratio of non-handheld vs. handheld phones after 3 years: 0.86, $90 \%$ CI: $0.47-$ 1.53). In a subsequent analysis, Dreyer et al. [20] analyzed the specific causes of death and found no increased risk of brain tumors or leukemia with greater use of mobile phones [25]. 
Table 3 Association of mobile phones use and brain tumors obtained from epidemiological studies [25]. Although some of the studies yielded significant results for analogue mobile phones, experts (including those of the studies) agree that the overall evidence from epidemiological studies does not suggest an association between mobile phone radiation and cancer (see results and discussion for details)

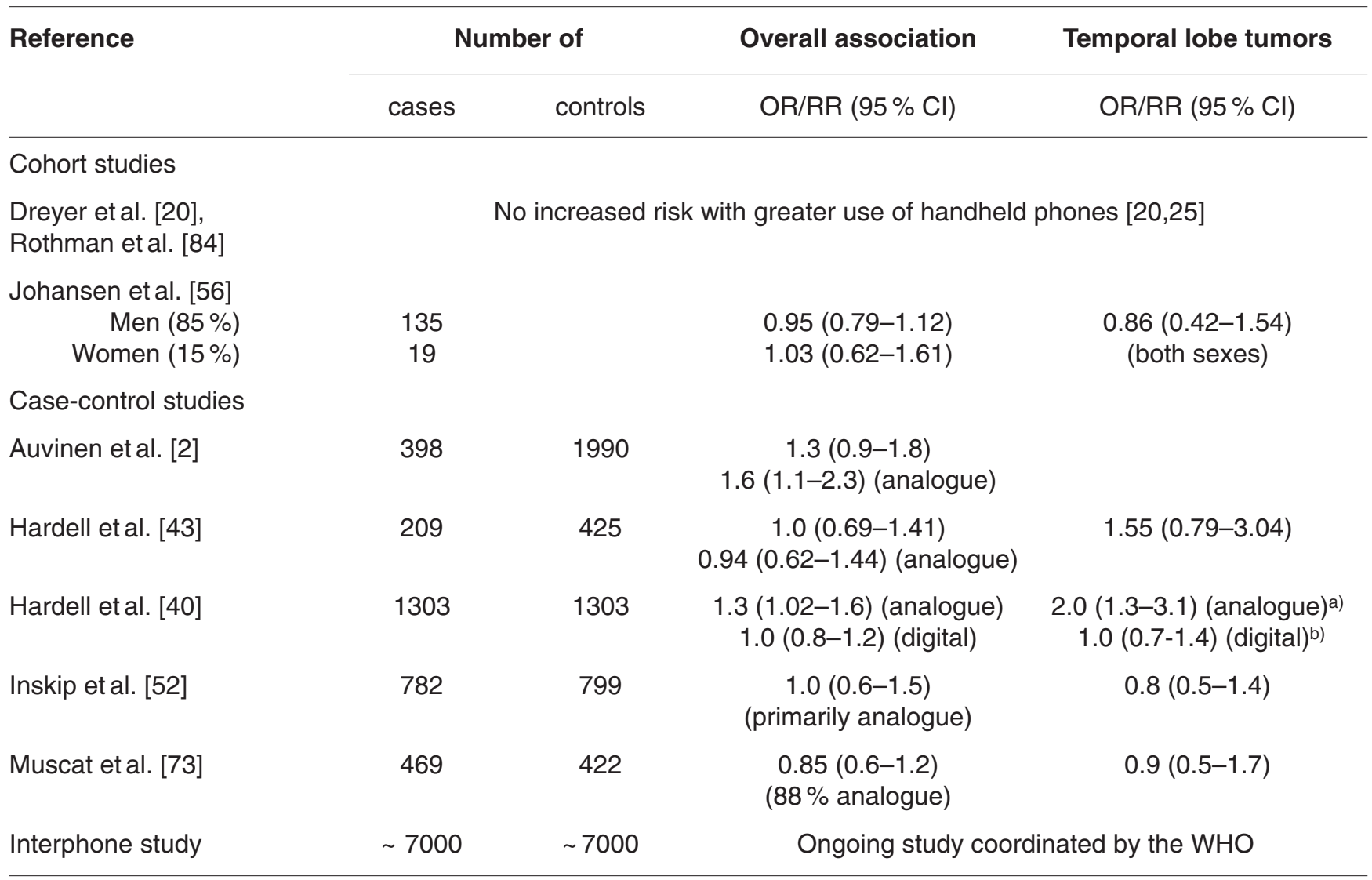

a) Latency $>10$ years, use $>85 \mathrm{~h}$

b) Latency $>5$ years, use $>55 \mathrm{~h}$

In a prospective cohort study with more than 420000 mobile phone users, Johansen et al. [56] determined the standardized incidence ratio (SIR) of cancer. This risk of all cancers was significantly reduced in men (0.86, $95 \%$ CI: $0.83-0.90)$, however, not in women (1.03, $95 \% \mathrm{CI}$ : 0.95-1.13). This finding was attributed to a decreased incidence of smoking-related cancers in men resulting from a confounding effect of social class, i.e. compared to the general population, mobile phone users are less likely to smoke. No significantly increased risk was found for brain tumors or leukemia [25].

Several case-control studies have been performed for brain tumors. Studies published by Inskip et al. [52], Muscat et al. [73] and Hardell et al. [43] did not show an increased risk for mobile telephone users (tab. 3).

Based on the initial study [43], Hardell et al. published a subsequent analysis [44] suggesting a marginal significant increased risk for tumors in the temporal, occipital or temporoparietal regions, where the an analogue mobile phone was used on the same side (RR 2.62 95\% CI: 1.02-6.71). This result, however, was based on statistical testing of many variables and it was criticized that the result could easily have occurred by chance $[25,93]$.

A second study by Hardell et al. reported a marginally significant increased risk of any type of brain tumors for the use of analogue, but not for digital phones [40]. This risk increased up to 10 years latency. A trend towards higher risk for longer exposure time was found at 10 years latency. At 5 years latency, however, the trend was in the opposite direction. The highest risk was seen in the temporal lobe and the risk for the ipsilateral use was higher than for the contralateral use of the phone. It was criticized, however, that this effect may also be a result of methodological problems of the study, such as misclassifications or recall bias [25]. Regarding the pathological subtypes, the highest risk was found for acoustic neurinomas (OR 3.5, $95 \%$ CI 1.8-6.8). This result, however, disagrees with previous results on acoustic neurinomas [52,56,72]. Further aspects of the study by Hardell et al. [40] are published in subsequent papers [41,42].

Auvinen et al. reported a significantly increased risk for brain tumors associated with subscription of an analogue mo- 
bile phones (Table 3). $50 \%$ of these tumors were gliomas (OR: 2.1, 95\% CI: 1.3-3.4). This result was assessed to be consistent with a small increased risk for brain cancer, but the association was considered to be weak and may have occurred by chance, misclassifications or due to uncontrolled confounding factors [25].

In a case-control study of uveal melanoma, Stang et al. [92] raised the hypothesis that mobile phone use is associated with an increased risk of uveal melanoma. A significant increased risk was reported (OR: 3.0, $95 \%$ CI: 1.4-6.3). The study, however, was criticized for several methodological deficiencies [53]. The hypothesis raised by this study was assessed by the Danish cohort study [55]. This study did not find an increased risk. Overall, there is no clear evidence of an association between mobile phone radiation and ocular cancer [22].

\section{Conclusion of epidemiological mobile phone studies}

Several studies on mobile phones have been carried out up to now. Concluding, no detrimental effects have been consistently observed $[25,28,48,93]$. Especially, no consistently increased risk for brain tumors was found although the exposure of the brain is higher than for other organs. Some positive associations have been reported in studies making multiple observations. These observations, however, fall short in strength and consistency to be interpreted in terms of cause and effect. Due to the inconsistency with other studies, it seems likely that they have occurred by chance variation [25]. On the other hand, the generally negative experimental evidence is consistent with the epidemiological results [25].

The results of the current epidemiological studies, however, are limited by several methodological deficiencies $[25,28,70,93]$. All studies are based on rather small number of cases and use a limited follow-up time in their analysis. Moreover, there is a substantial uncertainty in the exposure assessment, which is mostly estimated on the basis of questionnaires or telephone bills. Other uncontrolled factors may also lead to bias in the analysis. Although current results suggest, that there is no substantial increase of risk, a moderately increased risk cannot be ruled out and further high-quality studies are necessary.

\section{Ongoing studies}

Currently, a large case-control study is conducted to investigate a possible association between mobile phone use and the incidence of gliomas, menningiomas and acustic neurinomas. This ongoing study (INTERPHONE study) is coordinated by the World Health Organization (WHO) and is participated by 14 nations. In Germany, the participating institutions are the Universities of Bielefeld and Mainz and the German Cancer Research Center (DKFZ, Dept. of Environmental Epidemio$\operatorname{logy}$ ) in Heidelberg. The study is designed to detect a $50 \%$ risk increase [5] and to overcome the methodological shortcomings of the previous studies. First results of a Danish subpopulation indicate that there is no increased risks for acoustic neurinomas [14] which is in accordance with most of the pre- vious studies [52,56,72]. Further results of the INTERPHONE study are anticipated in the near future.

\section{Indirect effects}

\section{Interference with medical equipment}

Microwave radiation may interfere with medical equipment in hospitals and alter or inhibit its function. This may lead to significant hazards, if the patient depends on this device. Several types of medical equipment have been tested using radiation from digital mobile phones [65]. 45 of 479 of the devices tested with $900 \mathrm{MHz}$ and 14 of 457 devices tested at $1800 \mathrm{MHz}$ showed clinically relevant electromagnetic interference. The reviewed studies, however, showed a rather inconsistent interference pattern. The maximum distance at which clinically relevant interference occurred was 5 to $200 \mathrm{~cm}$ at $900 \mathrm{MHz}$ and 5 to $80 \mathrm{~cm}$ at $1800 \mathrm{MHz}$. Most of these events $(99 \%)$ occurred at a distance below $1 \mathrm{~m}$, which was considered to be a save distance [65].

\section{Interference with cardiac pacemakers}

Interference of mobile phone radiation with implanted pacemakers was investigated using experimental $[37,54]$ and clinical [45] study designs. In experimental studies, up to $40 \%$ of the investigated pacemakers have been shown to interfere with radiation of mobile phones [89]. The probability of interference, however, depends strongly on the combination of the type of pacemaker and mobile phone [54]. A distance of more than $20-25 \mathrm{~cm}$ between pacemaker and mobile phone was considered to be safe $[37,89]$. Below this distance, the risk of interference is highest in the operating mode where the owner of the pacemaker silently listens to his conversational partner [54,89]. Pacemakers are susceptible to electromagnetic interference from mobile phones using the $\mathrm{C}$ - as well as Dnetwork. No interference has been reported for mobile phones using the E-network [54,89].

In a clinical study Hayes et al. reported an overall interference of $20 \%$, and an incidence of clinically relevant symptoms of $7.2 \%$. Definitively clinically relevant symptoms occurred in $1.7 \%$ of all tests. In all of these cases, the mobile phone was placed directly over the pacemaker No interference occurred, if the phone was placed at the ear of the patients. In a case report, Yesil et al described loss of consciousness in one patient, after placing the mobile phone directly over the patients' pacemaker [108].

\section{Vehicle collisions}

An important health effect of mobile telephony is the association between mobile telephony and motor vehicle collisions [83]. This association is not related to the radiation of mobile phones itself, but results from distraction of the driver by the phone call. Redelmeier etal. [78] found that the risk of a collision when using a mobile phone was four times higher than the risk when a mobile phone was not being used (RR: $4.3,95 \%$ CI: 3.0-6.5). This risk is similar to that of driving 
with a blood alcohol level at the legal limit. Moreover, handfree kits did not offer a safety advantage over hand-held devices, i. e. legal regulations allowing only hand-free kits during driving are not based on scientific evidence [78,93]. This finding is consistent with the mortality rates published for hand-held and hand-free devices by Dreyer et al. [20]. A riskcomparison of mobile phone use and a conversation with a passenger on driving performance has not been performed [93]. A positive effect of mobile telephony certainly is the reduced time delay of emergency calls after a vehicle accident.

\section{Conclusions}

While there is no doubt about that microwave radiation can cause thermal effects which may be hazardous for humans, adverse health effects due to non-thermal microwave radiation have not been established [13,28,80,93]. Therefore, experts consider the ICNIRP protection guidelines to be save and do not recommend modifications of these guidelines $[28,75,93]$.

\section{Mobile phones and Cancer}

Most important, no association between mobile phone radiation and cancer was found in epidemiological studies, which is consistent with the general results of experimental studies. Although some experimental and epidemiological studies reported some positive associations, these results fail to be consistent with other studies and some of them suffer from methodological deficiencies. These studies do not warrant the conclusion of an association between mobile phone radiation and cancer.

\section{Evidence for biological effects}

There is some evidence suggesting that there may be biological effects due to non-thermal radiation. It is important, however, to understand that this does not necessarily mean that these effects lead to detrimental health effects in humans [93]. A major problem for the interpretation of such evidence arises from the fact that no convincing dose-response-mechanism has been established yet. Further research on possible basic mechanisms and their connection to observed biological effects is therefore necessary [74,93].

\section{Established risks}

Up to now, the only established risk was found for mobile phone use while driving a car. No safety advantage was obtained for the use of hands-free kits, which questions current legal regulations. The associated higher probability for vehicle collisions, however, is attributed to the distraction of the driver rather than to the microwave radiation itself. In addition, the radiation of mobile phones may interfere with medical devices or implanted pacemakers, which may pose a risk for a specific subpopulation [93]. The risk of interference, however, strongly depends on individual circumstances and is very difficult to predict.

\section{Completeness of scientific evidence}

Although the balance of evidence suggests that there are no detrimental effects associated with mobile phone radiation, health risks cannot be generally excluded. The follow-up time of epidemiological studies is still rather short. Moreover, the heterogeneity of the experimental and epidemiological results complicates the interpretation of these studies. It seems likely that any possible health effect is subtle and difficult to detect. Moreover, there may be subpopulations such as children, elderly people or patients, which are more susceptible to effects from mobile phone radiation than the general population. The special situation of exposed children was topic of the dedicated WHO workshop ,Sensitivity of children to EMF exposure (2004, Istanbul, Turkey)“.

To deal with the uncertainty for special subpopulations, a precautionary approach for the use of the mobile phone technology was recommended by the IEGMP [93]. These recommendations comprise aspects of planning, erection and operating of base stations as well as restricted use of mobile phones by children, near hospitals and while driving. Manufacturers should provide the SAR values to allow the customer to minimize his individual exposure [93].

It is generally agreed upon that further high-quality research is necessary $[28,80,93]$. Research priorities for invitro, in-vivo and for epidemiological studies have been outlined by Repacholi [80], the coordinator of the EMF project at the WHO. These research activities have to meet several criteria to be useful for health risk assessment [80]. One key issue for all types of investigations is a reliable exposure specification in terms of the SAR.

\section{Public risk perception}

The question whether mobile phone radiation causes adverse health effects in humans has also raised significant public concern. In contrast to the scientific discussion, the public discussion is not only driven by facts but also by anxiety, emotions, economical and political interests. The problem arises that the scientific method may well prove the significance of an increased health risk - if it exists. However, it cannot prove that there is no risk at any exposure level.

With respect to mobile phone radiation, the public perception may be distorted at least for three reasons: i) Not all scientific evidence may be available, ii) the public does not know how to weight each piece of evidence to arrive to a balanced evidence, and iii) the public may be mislead by prejudice or false information originating from other than scientific sources.

The scientific results on mobile phone radiation show that it is likely that there is no increased health risk, but strictly speaking this question is still open and further research is required. Due to the above distortions of the public perception, this indefinite answer may be misinterpreted, that there actually exists strong evidence for an increased health risk. 


\section{Risk communication to the public}

The scientific balance of evidence is developed by open discussions and subsequently published review articles. The basic result of this process has to be communicated in a simplified but still differentiated way to the public. Especially, contradictory material and open questions should be assessed. Reports of expert panels $[28,74,75,82,93]$ also provide valuable information as they also summarize the current status of research. In contrast to scientific review articles they focus not only on significance or non-significance of specific effects but also provide risk assessments and recommendations to the legal authorities. The content of such reports should also be communicated in a differentiated way to the public.

Finally, expertises requested by companies, organizations or by the government may also provide risk assessments. As the expertises are usually written by single experts or specialized institutes, their risk assessment may be more biased by opinions of single experts or institutions than that of expert panels. A solution to this problem may be to request more than one expertise. If these result in different risk assessments, there should be an open and transparent discussion about, where these differences result from.

This procedure was performed for expertises initiated by the Deutsche Telecom MobilNet GmbH [3,34,46,90], which requested expertises from four independent experts [34,90] and institutions $[3,46]$, respectively. The results of these expertises are in accordance with those of international reports [28,74,75, 82,93 ], concluding that there is no proven association between microwave exposure of mobile phones and adverse health effects in humans. There are, however, different assessments of scientific evidences between these four expertises. These differences were discussed and analysed by the authors of the expertises and additional experts during a workshop organized by the interdisciplinary research group „Mensch, Umwelt, Technik (MUT)“ of the Research Center in Jülich. As a result of this workshop, an additional report was published [106], describing the agreed and disagreed points of the expertises and analysing the reasons for the different risk assessments.

Government, public and companies are forced to deal in a responsible way with the relatively new mobile phone technology and their potential health risks in spite of the fact that the scientific body of evidence is incomplete. The situation is complicated by the fact that there are also financial interests involved. Nevertheless, any risk assessment and precautionary measures should be based on scientific grounds. To achieve acceptance of the resulting policy, there is no alternative to communicating these scientific grounds to the public in a highly transparent way. It is highly important that scientists participate in this process.

\section{References}

[1] Anane, R., Dilou P.-E., Taxile, M., Geffard, M., Crespeau F.-L., Veyret, B.: Effects of GSM-900 microwaves on DMBA-induced mammary gland tumors in female Sprague-Dawley rats. Radiat. Res. 160 (2003) 492-497
[2] Auvinen, A. Hietanen, M., Luukonen, R., Koskela, R.-S.: Braintumors and salivary gland cancers among cellular telephone users. Epidemiology 13 (2002) 356-359

[3] Benischke, A., Bunke D., Küppers, C., Wassilew-Reul, C.: Gutachten zum Erkenntnisstand zu möglichen gesundheitlichen Auswirkungen des Mobilfunks (im Auftrag der Deutsche Telecom MobilNet GmbH), Hrsg: Öko-institut e. V (2000-017-de), 2000

[4] Bernhardt, J.H.: Gesundheitliche Aspekte des Mobilfunks. Dtsch. Ärztebl. 13 (1999) A-845-A852

[5] Blettner, M., Michaelis, J., Wahrendorf, J.: Mobilfunk und Gesundheit. Dtsch. Ärztebl. 13 (1997) 847-850

[6] Bohr, H., Bohr, J.: Microwave enhanced kinetics observed in ORD studies of a protein. Bioelectromagnetics 21 (2000) 68-72

[7] Bohr, H., Brunak, S., Bohr, J.: Molecular wring resonances in chain molecules. Bioelectromagnetics 18 (1997) 187-189

[8] Borbely, A. A., Huber, R., Graf, T., Fuchs, B., Gallmann, E., Achermann, P.: Pulsed high-frequency electromagnetic field affects human sleep and sleep electroencephalogram. Neurosci. Lett. 275 (1999) 207-210

[9] Braune, S., Riedel, A., Schulte-Monting, J., Raczek, J.: Influence of a radiofrequency electromagnetic field on cardiovascular and hormonal parameters of the autonomic nervous system in healthy individuals. Radiat. Res. 158 (2002) 352-356

[10] Braune, S., Wrocklage, C., Raczek, J., Gailus, T., Lücking, G. H. Resting blood pressure increase during exposure to radio-frequency electromagnetic field. Lancet 351 (1998) 1857-1858

[11] Brusick, D., Albertini, R., McRee, D., Peterson, D., Williams, G., Hanawalt, P., Preston, J.: Genotocicity of radiofrequency radiation. Environ. Mol. Mutagen. 32 (1998) 1-16

[12] Chia, S.-E., Chia, H.-P., Tan, J.-S.: Prevalence of headache among handheld cellular telephone users in Singapore: A community study. Environ Health Perspect. 108 (2000) 1059-1062

[13] Chou, C.-K., D'Andrea, J. A.: Reviews of effects of RF fields on various aspects of human health: Introduction. Bioelectromagnetics 6 (Suppl.) (2003) 5-6

[14] Christensen, HC., Schüz, Joachim, Kosteljanetz, M., Poulsen, H. S., Thomsen, J., Johansen, C.: Cellular telephone use and risk of acustic neuroma. Am. J. Epidemiology 159 (2004) 277-283

[15] D'Andrea, J. A., Adair, E. R., de Lorge, J. O. : Behavioral and cognitive effects of microwave exposure. Bioelectromagnetics 6 (Suppl.) (2003) 39-62

[16] D'Andrea, J. A.: Behavioral evaluation of microwave irradiation. Bioelectromagnetics 20 (1999) 64-74

[17] D’Andrea, J.A., Chou, C.K., Johnston, A., Adair, E. R.: Microwave effects on the nervous system. Bioelectromagnetics 6 (Suppl.) (2003) $107-147$

[18] De Pomerai, D., Daniells, C., David, H., Allan, J., Duce, I., Mutwakil, M., Thomas, D., Sewell, P., Tattersall, J., Jones, D., Candidos, P.: Cell biology: Non-thermal heat-shock response to microwaves. Nature $\mathbf{4 0 5}$ (2000) 417-418

[19] De Pomerai, D., Dawe, A., Smith, B., Vasic, N., Thomas, D. W., Loader, B., Gregory, A.: Nematode heat-shock responses to electromagnetic fields: what is the underlying mechanism? Proceedings of the $3^{\text {rd }}$ International Workshop on biological effects of electromagnetic fields, 4.-8. 10. 2004, Kos, Griechenland (Abstract)

[20] Dreyer, N. A., Loughlin, J. E., Rothman, K. J.: Cause-specific mortality in cellular telephone users. JAMA 17 (1999) 1814-1816

[21] Eggert, S. Fischer, M., Goltz, S., Heinrich, W., Menzel, K., Reidenbach, H.-D.: Elektromagnetische Felder in Alltag und Beruf: Was wissen wir darüber? Strahlenschutzpraxis 2 (2001) 3-22

[22] Elder J. A.: Ocular effects of radiofrequency energy. Bioelectromagnetics 6 (Suppl.) (2003) 148-161

[23] Elder, J. A.: Survival and cancer in laboratory mammals exposed to radiofrequency energy. Bioelectromagnetics 6 (Suppl.) (2003) S. 101S. 106

[24] Elwood, J. M.: A critical review of epidemiologic studies of radiofrequency exposure and human cancers. Environ Health Perspect. 107 (Suppl. 1) (1999) 155-168 
[25] Elwood, J. M.: Epidemiological studies of radiofrequency exposures and human cancer. Bioelectromagnetics 6 (Suppl.) (2003) 63-73

[26] Eulitz, C., Ullsperger, P., Freude, G., Elbert, T.: Mobile phones modulate response patterns of human brain activity. Neuroreport 9 (1998) 3229-3232

[27] Finnie, J. W., Blumbergs, P.C., Manavis, J., Utteridge, T. D., Gebski, V., Davies, R. A., Vernon-Roberts, B., Kuchel, T.R.: Effect of longterm mobile communication microwave exposure on vascular permeability in mouse brain. Pathology. 34 (2002) 344-347

[28] Flynn, G. (chairman): A review of potential risks of radiofrequency fields from wireless telecommuncation devices. Hrsg: Royal Society of Canada, Ottawa, Ontario, 1999

[29] Frei, M. R., Berger, R. E., Dusch, S. J., Guel, V., Jauchem, J. R., Merrit, J. H., Stedham, M. A.: Chronic exposure of cancer-prone mice to lowlevel $2450 \mathrm{MHz}$ radiofrequency radiation. Bioelectromagnetics 19 (1998) 20-31

[30] Frei, M.R., Jauchem, J.R., Dusch, S.J., Merrit, J.H., Berger, R.E. Stedham, M. A.: Chronic low-level $(1.0 \mathrm{~W} / \mathrm{kg})$ exposure of mammary cancer-prone mice to $2450 \mathrm{MHz}$ microwaves. Radiat. Res. 150 (1998) $568-576$

[31] Freude, G., Ullsperger, P., Eggert, S., Ruppe, I.: Effects of microwaves emitted by cellular phones on human slow brain potentials. Bioelectromagnetics 19 (1998) 384-387

[32] Freude, G., Ullsperger, P., Eggert, S., Ruppe, I.: Microwaves emitted by cellular telephones affect human slow brain potentials. Eur. J. Appl. Physiol. 81 (2000) 18-27

[33] Fritze, K., Sommer, C., Schmitz, B., Mies, G., Hossmann, K. A., Kiess ling, M., Wiessner, C.: Effect of global system for mobile communication (GSM) microwave exposure on blood-brain barrier permeability in rat. Acta Neuropathol. 94 (1997) 465-470

[34] Glaser, R.: Darstellung und Bewertung des wissenschaftlichen Erkenntnisstandes zu möglichen gesundheitlichen Auswirkungen des Mobilfunks in Relation zu bestehenden Empfehlungen und Normen. 2000

[35] Goldstein, L. S., Kheifets L., van Deventer, E, Repacholi, M.: Comments on „Long-term exposure of Eu-Pim1 transgenic mice to $898.4 \mathrm{MHz}$ microwaves does not increase Lymphoma incidence" by Utteridge et al., Radiat. Res. 158, 357-364 (2002). Radiat. Res. 159 (2003) 275-276

[36] Goldstein, L. S., Kheifets, L., van Deventer, E., Repachili, M.: Further comments on „Long-term exposure of E $\mu$-Pim1 transgenic mice to 898.4 MHz microwaves does not increase Lymphoma incidence“ by Utteridge et al., Radiat. Res. 158, 357-364 (2002). Radiat. Res. 159 (2003) 835

[37] Grant, F.H. Schlegel, R.E.: Effects of an increased air gap on the in vitro interaction of wireless phones with cardiac peacemakers. Bioelectromagnetics 21 (2000) 485-490

[38] Haarala, C., Bjornberg, L., Ek, M., Laine, M., Revonsuo, A., Koivisto, M., Hamalainen, H.: Effect of a $902 \mathrm{MHz}$ electromagnetic field emitted by mobile phones on human cognitive function: A replication study. Bioelectromagnetics 24 (2003) 283-388

[39] Hamblin, D. L., Wood, A. W., Croft, R. J., Stough, C.: Examining the effects of electromagnetic fields emitted by GSM mobile phones on human event-related potentials and performance during an auditory task. Clin. Neurophysiol. 115 (2004) 171-178

[40] Hardell, L., Hallquist, A., Hansson Mild, K., Carlberg, M., Pahlson, A., Lilja, A.: Cellular and cordless telephones and the risk for brain tumors. Eur. J. Cancer Prev. 11 (2002) 377-386

[41] Hardell, L., Mild, K. H., Carlberg, M.: Case-control study on the use of cellular and cordless phones and the risk for malignant brain tumours. Int. J. Radiat. Biol. 78 (2002) 931-936

[42] Hardell, L., Mild, K. H., Carlberg, M.: Further aspects on cellular and cordless telephones and brain tumors. Int. J. Oncol. 22 (2003) 399-407

[43] Hardell, L., Näsman, A., Pahlson, A., Hallquist, A., Mild, K. H.: Use of cellular telephones and the risk for brain tumors: A case-control study. Int. J. Oncol. 15 (1999) 113-116

[44] Hardell, L., Nasman, A., Pahlson, A., Hallquist, A.: Case-control study on radiology work, medical X-ray investigations, and use of cellular telephones as risk factors for brain tumors. Med. Gen. Med. 2 (2000) E2
[45] Hayes, D. L., Wang, P. J., Reynolds, D. W., Estes III, M., Griffith, J. L. Steffens, R.A., Carlo, G. L., Findlay G. K., Johnson, C. M.: Interference with cardiac pacemakers by cellular telephones. N. Engl. J. Med. 336 (1997) 1473-1479

[46] Hennies, K., Neitzke, H.-P., Voigt, H.: Mobilfunk und Gesundheit: Bewertung des wissenschaftlichen Erkenntnisstandes unter dem Gesichtspunkt des Gesundheitsschutzes (im Auftrag der Deutsche Telecom MobilNet $\mathrm{GmbH}$ ) Hrsg: ECOLOG-Institut für sozial-ökologische Forschung und Bildung $\mathrm{GmbH}, 2000$

[47] Hermann, D. M., Hossmann, K.-A.: Neurological effects of microwave exposure related to mobile communication. J. Neurol. Sci. 152 (1997) $1-14$

[48] Heynick, L. N., Johnston, S. A., Mason, P. A.: Radio frequency electromagnetic fields: cancer, mutagenesis, and genotoxicity. Bioelectromagnetics 6 (Suppl.) (2003) 74-100

[49] Huber, R., Graf, T., Cote, K. A., Wittmann, L., Gallmann, E., Matter, D., Schuderer, J., Kuster, N., Borbely, A. A., Achermann, P.: Exposure to pulsed high-frequency electromagnetic field during waking affects human sleep EEG. Neuroreport 11 (2000) 3321-3325

[50] Huber, R., Treyer, V., Borbely, A. A., Schuderer, J., Gottselig, J. M., Landolt, H. P., Werth, E., Berthold, T., Kuster, N., Buck, A., Achermann, P.: Electromagnetic fields, such as those from mobile phones, alter regional cerebral blood flow and sleep and waking EEG. J. Sleep Res. 11 (2002) 289-295

[51] Hyland, G. J.: Physics and biology of mobile telephony. Lancet 356 (2000) 1833-1836

[52] Inskip, P. D. Tarone, R. E., Hatch, E. E., Wilcosky, T. C., Shapiro, W. R., Selker, R. G., Fine, H. A., Black, P. M., Loeffler, J. S., Linet, M. S.: Cellular-telefone use and brain tumors. N. Engl. J. Med. 344 (2001) 79-86

[53] Inskip, P.: Frequent radiation exposures and frequency dependent effects: the eyes have it. Epidemiology 12 (2001) 1-4

[54] Irnich, W., Batz, L., Müller, R., Tobisch, R.: Störbeeinflussung von Herzschrittmachern durch Mobilfunkgeräte. Herzschrittmacher 15 (1995) 5-20 und 45-49

[55] Johansen. C., Boice, J. D., McLaughlin, J. K., Christensen, H. C., Olsen, J. H.: Mobile phones and malignant melanoma of the eye. Br. J. Cancer 86 (2002) 348-349

[56] Johanson, C., Boice, J. D., McLaughkin, J. K., Olsen, J. H. Cellular telephones and Cancer - a nationwide cohort study in Denmark. J. Natl. Cancer Inst. 93 (2001) 203-207

[57] Kaiser, F.: External signals and internal oscillation dynamics: biophysical aspects and modelling approaches for interactions of weak electromagnetic fields at the cellular level. Bioelectrochem. Bioenerg. 41 (1996) 3-18

[58] Koivisto, M., Krause, C. M., Revonsuo, A., Laine, M., Hamalainen, H. The effects of electromagnetic field emitted by GSM phones on working memory. Neuroreport 11 (2000) 1641-1643

[59] Koivisto, M., Revonsuo, A., Krause, C., Haarala, C., Sillanmaki, L., Laine, M., Hamalainen, H.: Effects of $902 \mathrm{MHz}$ electromagnetic field emitted by cellular telephones on response times in humans. Neuroreport 11 (2000) 413-415

[60] Krause, C. M., Haarala, C., Sillanmaki, L., Koivisto, M., Alanko, K., Revonsuo, A., Laine, M., Hamalainen, H.: Effects of electromagnetic field emitted by cellular phones on the EEG during an auditory memory task: a double blind replication study. Bioelectromagnetics $\mathbf{2 5}$ (2004) 33-40

[61] Krause, C. M., Sillanmaki, L., Koivisto, M., Haggqvist, A., Saarela, C., Revonsuo, A., Laine, M., Hamalainen, H.: Effects of electromagnetic fields emitted by cellular phones on the electroencephalogram during a visual working memory task. Int. J. Radiat. Biol. 76 (2000) 1659-1667

[62] Krause, C. M., Sillanmaki, L., Koivisto, M., Haggqvist, A., Saarela, C., Revonsuo, A., Laine, M., Hamalainen, H.: Effects of electromagnetic field emitted by cellular phones on the EEG during a memory task. Neuroreport 11 (2000) 761-764

[63] Kundi, M.: Comments on „Long-term exposure of E $\mu$-Pim1 transgenic mice to $898.4 \mathrm{MHz}$ microwaves does not increase Lymphoma incidence“ by Utteridge et al., Radiat. Res. 158, 357-364 (2002). Radiat. Res. 159 (2003) 274 
[64] La Regina, M., Moros, E. G., Pickard, W. F., Strambe, W. L., Baty, J., Poti Roti, J.L.: The effect of chronic exposure to 835.62 MHz FDMA or $847.74 \mathrm{MHz}$ CDMA radiofrequency radiation on the incidence of spontaneous tumors in rats. Radiat. Res. 160 (2003) 143-151

[65] Lawrentschuk, N., Bolton, D. M.: Mobile phone interference with medical equipment and ist clinical relevance: a systematic review. Med. J. Austral. 181 (2004) 145-149

[66] Lerchl, A.: Comments on „Long-term exposure of E $\mu$-Pim1 transgenic mice to $898.4 \mathrm{MHz}$ microwaves does not increase Lymphoma incidence" by Utteridge et al., Radiat. Res. 158, 357-364 (2002). Radiat. Res. 159 (2003) 276

[67] Lin, J. C.: Effects of cell-phone radiation an lymphoma-prone mice. IEEE microwave magazine 4 (2003) 22-28

[68] Mann, K., Röschke, J.: Effects of pulsed high-frequency electromagnetic fields on human sleep. Neuropsychobiology 33 (1996) 41-47

[69] Meltz, M.L.: Radiofrequency exposure and mammalian cell toxicity, genotoxicisity, and transformation. Bioelectromagnetics 6 (Suppl.) (2003) 196-213

[70] Mild, K. H., Hardell, L., Kundi, M., Mattsson, M.-O.: Mobile telephones and cancer: Is there really no evidence of an association? (Review). Int. J. Mol. Med. 12 (2003) 67-72

[71] Moulder, J. E. Erdreich, L. S., Malyapa, R. S., Merrit, J., Pickard, W. E., Vijayalaxmy, D.Z.: Cell phones and cancer: What is the evidence for a connection? Radiat. Res. 151 (1999) 513-531

[72] Muscat, J. E., Malkin, M. G., Shore, R. E., Thompson, S., Neugut, A. I., Stellman, S.D., Bruce, J.: Handheld cellular telephone and risk of acoustic neuroma. Neurology 58 (2002) 1304-1306

[73] Muscat, J.E., Malkin, M.G., Thompson, S., Shore, R.E., Stellman, S. D., McRee, D., Neugut, A. I., Wynder, E. L.: Handheld cellular telephone use and risk of brain cancer. JAMA 284 (2000) 3001-3007

[74] National Radiation Protection Board: Health effects from radiofrequency electromagnetic fields. Oxfordshire, Großbritannien, 2004

[75] National Radiation Protection Board: Review of the scientific evidence for limiting exposure to electromagnetic fields $(0-300 \mathrm{GHz})$. Oxfordshire, Großbritannien, 2003

[76] Oftedal, G., Sandström, M., Mild, K. H.: Symptoms experienced in connection with mobile phone use. Occup. Med. 50 (2000) 237-245

[77] Preece, A. W., Iwi, G., Davies-Smith, A., Wesnes, K., Butler, S., Lim, E., Varey, A.: Effect of a $915 \mathrm{MHz}$ simulated mobile phone signal on cognitive function in man. Int. J. Radiat. Biol. 75 (1999) 447456

[78] Redelmeier, D. A., Tibsshirani, R. J.: Association between cellular-telephone calls and motor vehicle collisions. N. Engl. J. Med. 336 (1997) 453-458

[79] Repacholi, M. H. Basten, A., Gebski, V., Noonan, D., Finnie, J., Harris, A.W.: Lymphomas in E $\mu$-Pim1 transgenic mice exposed to pulsed $900 \mathrm{MHz}$ electromagnetic fields. Radiat. Res. 147 (1997) 631-640

[80] Repacholi, M.H.: Low-level exposure to radiofrequency electromagnetic fields: Health effects and research needs. Bioelectromagnetics 19 (1998) 1-19

[81] Repacholi, M.H.: Radiofrequency field exposure and cancer: What do the laboratory studies suggest? Environ Health Perspect. 105 (Suppl. 6) (1997) 1565-1568

[82] Rössli, M., Rapp, R.: Hochfrequente Strahlung und Gesundheit. Hrsg.: Amt für Umwelt, Wald und Landschaft. BUWAL. Umweltmaterialien Nr. 62, Bern, Schweiz, 2003

[83] Rothman, K. J.: Epidemiological evidence on health risks of cellular telephones. Lancet 356 (2000) 1837-1840

[84] Rothmann, K. J. Loughlin, J.E., Funch D.P., Dreyer, N.E.: Overall mortality of cellular telephone customers. Epidemiology 7 (1996) 303305

[85] Ruppe, I., Hentschel, K., Eggert S., Neuschulz, H., Ullsperger P., Freude, G., Enderlein, G., et al.: Wirkungen von niederfrequent gepulsten Feldern auf den Menschen - Fallbeschreibungen und Untersuchungen an Probanden. In: Funkanwendungen - Technische Perspektiven, biologische Wirkungen und Schutzmaßnahmen. Veröffentlichung der Strahlenschutzkommission, Band 38123-134, Urban \& Fischer, München, Jena (1999)
[86] Salford, L. G., Brun, A., Sturesson, K., Eberhardt, J. L., Persson, B. R.: Permeability of the blood-brain barrier induced by $915 \mathrm{MHz}$ electromagnetic radiation, continuous wave and modulated at $8,16,50$, and 200 Hz. Microsc. Res. Tech. 27 (1994) 535-542

[87]Salford, L. G., Brun, A. E., Eberhardt, J. L., Malmgren, L., Persson, B. R Nerve cell damage in mammalian brain after exposure to microwaves from GSM mobile phones. Environ Health Perspect. 111 (2003) 881-883

[88] Sandström, M., Wilen, J., Oftedal, G., Mild, K. H.: Mobile phone use and subjective symptoms. Comparison of symptoms experienced by users of analogue and digital mobile phones. Occup. Med. 51 (2001) 25-35

[89] Silny, J.: Beeinflussung von Implantaten und Körperhilfen durch Mobilfunkeinrichtungen. In: Funkanwendungen - Technische Perspektiven, biologische Wirkungen und Schutzmaßnahmen. Veröffentlichung der Strahlenschutzkommission, Band 38, 135-148, Urban \& Fischer, München, Jena (1999)

[90] Silny, J.: Gesundheitliche Auswirkungen der Mikrowellen von Mobilfunkanlagen im D-Netz. Aachen, 2000

[91] Silny, J.: Gesundheitsrelevante Wirkungen hochfrequenter elektromagnetischer Felder des Mobilfunks und anderer neuer Kommunikationssysteme. Umweltmagazin in Forschung und Praxis 3 (2004), 127-136

[92] Stang, A., Anastassiou, G., Ahrens, W., Bromen, K., Bornfeld, N., Jöckel, K.-H.: The possible role of radiofrequency radiation in the development of uveal melanoma. Epidemiology 12 (2001) 7-12

[93] Stewart, W. (chairman): Mobile phones and health. Report of the Independent Expert Group on Mobile Phones (IEGMP), Hrsg: Independent Expert Group on Mobile Phones, 2000

[94] Tahvanainen, K., Nino, J., Halonen, P., Kuusela, T., Laitinen, T., Lansimies, E., Hartikainen, J., Hietanen, M., Lindholm, H.: Cellular phone use does not acutely affect blood pressure or heart rate of humans. Bioelectromagnetics 25 (2004) 73-83

[95] Toler, J. C., Shelton, W. W., Frei, M. R., Merrit, J. H., Stedham, M. A Long-term, low-level exposure of mice prone to mammary tumors to $435 \mathrm{MHz}$ radiofrequency radiation. Radiat. Res. 148 (1997) 227-234

[96] Tsurita, G., Nagawa, H., Ueno, S., Watanabe, S., Taki, M.: Biological and morphological effects on the brain after exposure of rats to a $1439 \mathrm{MHz}$ TDMA field. Bioelectromagnetics 21 (2000) 364-371

[97] Utteridge, T. D., Gebski, V., Finnie, J. W., Vernon-Roberts, B., Kuchel, T. R.: Long-term exposure of E $\mu$-Pim1 transgenic mice to $898.4 \mathrm{MHz}$ microwaves does not increase Lymphoma incidence. Radiat. Res. 158 (2002) 357-364

[98] Utteridge, T. D., Gebski, V., Finnie, J. W., Vernon-Roberts, B., Kuchel, T. R.: Response to the Letters to the Editor sent by (1) Kundi, (2) Goldstein/Kheifets/van Deventer/Repacholi, and (3) Lerchel: Radiat. Res. 159 (2003) 276-278

[99] Utteridge, T.: Response to the Letter of Goldstein et al. Radiat. Res. 159 (2003) 835-836

[100] Van Leeuven, G. M., Lagendijk, J. J., Van Leersum, B. J., Zwamborn A. P., Hornsleth, S. N., Kotte, A. N.: Calculation of change in brain temparature due to exposure to a mobile phone. Phys. Med. Biol. 44 (1999) 2367-2379

[101] Verschaeve, L. Maes, A.: Genetic, carcinogenic and teratogenic effects of radiofrequency fields. Mutat. Res. 410 (1998) 141-165

[102] von Klitzing, L.: Low-Frequency pulsed electromagnetig fields influence EEG of man. Phys. Med. XI (1995) 77-80

[103]Wagner, P., Röschke, J., Mann, K., Fell, J., Hiller, W., Frank, C., Grozinger, M.: Human sleep EEG under the influence of pulsed radio frequency electromagnetic fields. Results from polysomnographies using submaximal high power flux densities. Neuropsychobiology 42 (2000) 207-212

[104] Wagner, P., Röschke, J., Mann, K., Hiller, W., Frank, C.: Human sleep under the influence of pulsed radiofrequency electromagnetic fields: a polysomnographic study using standardized conditions. Bioelectromagnetics; 19 (1998) 199-202

[105] Wainwright, P.: Thermal effects of radiation from cellular telephones Phys. Med. Biol. 45 (2000) 2363-2372

[106] Wiedemann, P., Schütz, H., Thalmann A.: Risikobewertung im wissenschaftlichen Dialog. Hrsg: Forschungszentrum Jülich, 2002

[107] World Health Organization (WHO): Electromagnetic fields and public health. Fact Sheet $N^{\circ} 193(2000)$ 
[108] Yesil, M., Bayata, S., Postaci, N, Aydin, C.: Pacemaker Inhibition and asystole in a pacemaker dependent patient. Pacing Clin. Electrophysiol. 18 (1995) 1963

[109] Zwamborn, A.P. M., Vossen, S.H. J.A., van Leersum, B. J. A. M., Ouwens, M. A., Mäkel, W. N.: TNO-Report: Effects of global communication systems radio-frequency fields on well being and cognitive function of human subjects with and without subjective complaints. TNO Physics and Electronics Laboratory, Den Hague, Niederlande, 2003

Received 06. 10.2004; accepted for publication 13.01.2005.

\section{Correspondence to:}

PD Dr. Christian P. Karger

Deutsches Krebsforschungszentrum

Abteilung Medizinische Physik in der Strahlentherapie (E040)

Im Neuenheimer Feld 280

D-69120 Heidelberg,

Phone: +49-6221-422596

Fax: +49-6221-422572

e-mail: c.karger@dkfz.de 